\title{
Detection of diphtheria toxin in culture supernates of Corynebacterium diphtheriae and C. ulcerans by immunoassay with monoclonal antibody
}

\author{
G. HALLAS, T. G. HARRISON, D. SAMUEL and G. COLMAN*
}

Division of Microbiological Reagents and Quality Control, and "Division of Hospital Infection, Central Public Health Laboratory, 61 Colindale Avenue, London NW9 5HT

\begin{abstract}
Summary. Monoclonal antibody (MAb) to diphtheria toxin was produced in mouse hybridomas, and shown by ELISA to be of sub-class $\operatorname{IgG}_{1}$. Hybridomas were inoculated into mice to produce ascitic fluid from which MAb was purified by caprylic acid. The MAb was shown by immunoblotting to be directed against the $A$ fragment of the toxin and also against the intact toxin molecule. After conjugation with fluorescein isothiocyanate, it was used in an immunoassay to detect toxin in culture supernates of Corynebacterium diphtheriae and $C$. ulcerans. The assay correlated well with the Elek test and with virulence in guinea-pigs; but it gave occasional false positive results, probably by binding of MAb to defective toxin.
\end{abstract}

\section{Introduction}

Although diphtheria is now an uncommon disease in the UK, sporadic cases occur which are mainly imported from abroad. Therefore, there is still a need for the clinical laboratory to identify accurately toxin-producing strains of Corynebacterium diphtheriae. Toxin tests are traditionally done by the Elek method, ${ }^{1}$ with confirmation of virulence in guinea-pigs where animal facilities are available. However, discrepancies amongst laboratories using the Elek test have been reported. ${ }^{2}$ The aim of this study was to produce a monoclonal antibody (MAb) to diphtheria toxin, to investigate its use in an additional laboratory test for toxin production, and to compare this test with existing methods.

\section{Materials and methods}

\section{Diphtheria toxin and toxoid}

Preparations of toxin and toxoid were supplied by Wellcome Reagents Ltd. The toxin solution contained $5100 \mathrm{Lfu} / \mathrm{ml}$ and the toxoid preparation $3400 \mathrm{Lfu} / \mathrm{ml}$.

\section{Immunisation of mice}

BALB/c mice were immunised with either diphtheria toxin or toxoid. The protein content of these preparations was estimated by a dye binding assay (Bio-Rad Labora-

Received 23 Nov. 1989; accepted 18 Jan. 1990. tories). Immunisation was by intraperitoneal injection with either $100 \mu \mathrm{g}$ of toxoid or $50 \mu \mathrm{g}$ of toxin in Freund's incomplete adjuvant with $50 \mu \mathrm{g}$ of the muramyl dipeptide (MDP), N-acetylmuramyl L-alanyl D-isoglutamine (Sigma). With toxoid, mice were given three further injections of $10 \mu \mathrm{g}$ of toxoid in adjuvant with MDP at 2week intervals. With toxin, they were rested for 4 weeks after the initial injection because of adverse reactions; two injections of $10 \mu \mathrm{g}$ of toxin were then given, 2 weeks apart. The final inoculation for both groups of mice was $10 \mu \mathrm{g}$ of toxin or toxoid intravenously, 19 days after the previous injection. Their spleens were removed aseptically 3 days later.

\section{Monoclonal antibody ( $M A B$ ) to diphtheria toxin}

Production. Spleen cells from the immunised mice were fused with mouse myeloma cell line JK-Ag 8653, by standard methods. ${ }^{3,4}$ Culture supernates from hybridomas were screened by an enzyme immunoassay as described below. In the initial screening, 20 hybridoma cultures gave positive test results, and 11 of these were cloned by limiting dilution. Ascitic fluid was obtained with two clones by re-introducing each clone into mice pre-treated with pristane.

Screening of clones for antibody. Wells of a microtitration plate (Nunc, Immunoplate II) were coated with $0.1 \mathrm{ml}$ of a 1 in 1200 dilution of toxin per well, or a 1 in 800 dilution of toxoid, in $0.05 \mathrm{M}$ carbonate buffer (pH 9.6) for $48 \mathrm{~h}$ at $4^{\circ} \mathrm{C}$. The coated plates were washed three times with phosphate-buffered saline (PBS) containing Tween $200.05 \% \mathrm{v} / \mathrm{v}$ (TW). Culture supernates from hybridomas were added and incubated at $37^{\circ} \mathrm{C}$ for $1 \mathrm{~h}$. Plates were washed as previously and then incubated at $37^{\circ} \mathrm{C}$ for $1 \mathrm{~h}$ 
with a 1 in 500 dilution of anti-mouse polyvalent immunoglobulin and alkaline phosphatase conjugate (Sigma). Bound antibody was detected by the addition of phosphatase substrate (Sigma). Plates were examined visually for colour development.

Characterisation and purification. The isotype of the secreted antibody was determined by ELISA. Briefly, antibody was immobilised in wells of a microtitration plate coated with toxin, $0.425 \mathrm{Lfu} /$ well. Bound antibody was then detected with anti-mouse horseradish-peroxidase conjugate specific for IgM (Miles Scientific), IgG whole molecule (Tissue Culture Services Ltd) or IgG subclass (ICN Immunobiologicals), and the appropriate substrate.

MAb was purified from ascitic fluid with caprylic acid. $^{5,6}$

\section{Immunoblotting (Western blotting)}

Samples of toxin and toxoid, treated with sodium dodecyl sulphate (SDS)-mercaptoethanol, were separated by SDS polyacrylamide gel electrophoresis (SDS-PAGE) in acrylamide gels $10 \%$ with a 'Mighty Small' slab gel apparatus (Hoeffer) and the buffer system of Laemmli. ${ }^{7}$ Proteins were transferred to nitrocellulose by electrophoresis. ${ }^{8}$ The nitrocellulose was then incubated for $18 \mathrm{~h}$ at $4^{\circ} \mathrm{C}$ in a solution of bovine serum albumin $5 \%$. The blot was washed in PBS; and a solution of MAb, diluted 1 in 250 in PBS-TW and horse serum (HS) $5 \%$, was layered on to the nitrocellulose and incubated at room temperature for $1 \mathrm{~h}$. The blots were washed as before and alkalinephosphatase-conjugated anti-mouse IgG (Sigma) was added and incubated for $1 \mathrm{~h}$. After washing, the bound MAb was detected with 5-bromo-4-chloro-3-indolyl phosphate and nitro-blue tetrazolium as the substrate. ${ }^{9}$

\section{Strains of bacteria}

Strains of $C$. diphtheriae and $C$. ulcerans were selected from recent isolates sent to the Division of Hospital Infection for investigation, from strains held by the National Collection of Type Cultures (NCTC), Colindale, and from cultures kindly provided by Dr J.M.S. Dixon, Provincial Laboratory of Public Health, Alberta, Canada.

Elek test for toxin production. The toxigenicity of the strains was examined as previously described. ${ }^{10}$ Strains NCTC 10648 (rapid toxin producer), NCTC 3984(weakly toxigenic) and NCTC 10356 (non-toxigenic) were included as controls in each Elek plate.

Virulence in guinea-pigs. One of two guinea-pigs, each weighing $c .250 \mathrm{~g}$, was given 100 units of diphtheria antitoxin (Swiss Serum and Vaccine Institute, Bern) by intraperitoneal injection. A suspension of the test strain was prepared by washing the growth from an 18-24-h Loeffler-slope culture with $2 \mathrm{ml}$ of peptone water; $0.2 \mathrm{ml}$ of this suspension was injected subcutaneously into the protected (control) and unprotected (test) animal. Animals that died were examined post-mortem for characteristic effects of diphtheria toxin.
Growth of cultures. Strains were grown in $3 \mathrm{ml}$ of either proteose peptone maltose (PPM) medium $^{11}$ (Proteose Peptone No. 3 [Difco] $4 \% \mathrm{w} / \mathrm{v}$, maltose $0.6 \% \mathrm{w} / \mathrm{v}$ ), or Elek broth ${ }^{12}$ (proteose peptone $2 \% \mathrm{w} / \mathrm{v}$, maltose $0.3 \%$ $\mathrm{w} / \mathrm{v}, \mathrm{NaCl} 0.5 \% \mathrm{w} / \mathrm{v}$, lactic acid $0.07 \% \mathrm{w} / \mathrm{v}, \mathrm{NaOH} 0.06 \%$ w/v). After incubation for $18-24 \mathrm{~h}$ at $37^{\circ} \mathrm{C}$, cultures were centrifuged to remove the bacteria and the supernates were filtered through a $0 \cdot 2-\mu \mathrm{m}$ Acrodisc R filter (Gelman Sciences). Thiomersal $0.02 \%$ was added as a preservative and samples were stored at $4^{\circ} \mathrm{C}$.

\section{Preparation of $M A$ A labelled with fluorescein isothiocyanate (FITC)}

To $2 \mathrm{mg}$ of purified MAb in $0.1 \mathrm{M}$ sodium carbonate and $0.15 \mathrm{M} \mathrm{NaCl}, 13.7 \mu \mathrm{l}$ of an ethanolic solution of FITC $(5 \mathrm{mg} / \mathrm{ml})$ was added and stirred for $1 \mathrm{~h}$ at room temperature. The FITC-conjugated antibody was separated from free FITC by gel filtration on Sephadex G25 in a PD10 column (Pharmacia), and the fractions containing conjugate were pooled. Antibody-FITC conjugates were stored at $4{ }^{\circ} \mathrm{C}$ in glycerol $20 \%$ containing azide $0.08 \%$.

\section{Enzyme immunoassay (EIA) for diphtheria toxin}

Microtitration plates (Nunc, Immunoplate II) were coated with $0 \cdot 1 \mathrm{ml}$ of the purified MAb $(5 \mu \mathrm{g} / \mathrm{ml}$ in PBS) for $48 \mathrm{~h}$ at $4^{\circ} \mathrm{C}$. The plates were washed three times with PBS-TW, and filtered culture supernates $(0.1 \mathrm{ml})$ were added. They were incubated in a moist chamber at $37^{\circ} \mathrm{C}$ for $1 \mathrm{~h}$, and washed as before. A 1 in 1000 dilution of FITC-conjugated MAb in PBS-TW-HS was added; and they were incubated as before, and washed again. A peroxidase-conjugated anti-FITC MAb $^{6}$ diluted in PBSTW-HS was added; and they were incubated for $1 \mathrm{~h}$ at $37^{\circ} \mathrm{C}$, washed, and then incubated for $30 \mathrm{~min}$ at room temperature with $100 \mu 1$ of a peroxidase substrate $(42 \mathrm{mM}$ $3,3^{\prime}, 5,5^{\prime}$-tetramethylbenzidine and $1.3 \mathrm{mM} \mathrm{H}_{2} \mathrm{O}_{2}$ in $0 \cdot 1 \mathrm{M}$ sodium acetate and citric acid buffer, $\mathrm{pH} \mathrm{6.0)}$. The reaction was stopped with $0.05 \mathrm{ml}$ of $2 \mathrm{M} \mathrm{H}_{2} \mathrm{SO}_{4}$, and the optical density (OD) was measured at $450 \mathrm{~nm}$ in a Titertek Multiscan MCC/340 MK II (Flow Laboratories).

\section{Results}

Two of the hybridoma cultures were stable after two cloning procedures. They were both derived from the same mouse which had been immunised with diphtheria toxoid. The antibody class secreted by both culture supernates was shown by ELISA to be $\mathrm{IgG}_{1}$. Both clones were inoculated into mice for the production of ascitic fluid. Antibody purified from the fluid by caprylic acid, designated MAb 1 and MAb 2, was used in further studies.

\section{Immunoblotting}

Samples of toxin and toxoid, treated with SDSmercaptoethanol and separated by SDS-PAGE, 
were stained with Coomassie Blue (fig. 1). The toxin dissociated into two components which corresponded approximately to the published molecular size of fragment $\mathrm{A}(21 \mathrm{Kda})$ and fragment B ( $37 \mathrm{Kda})$. The toxoid sample remained largely intact after SDS-mercaptoethanol treatment and was present as a single major band $(58 \mathrm{Kda}){ }^{13}$ Fig. 2 shows a nitrocellulose blot of samples of toxin and toxoid, separated by SDS-PAGE and stained with each MAb. Identical reactions were obtained with both MAbs. Bands were visible in positions on the blot corresponding to the intact toxin molecule and also to the fragment of smaller molecular weight (fragment $\mathrm{A}$ ) indicating that $\mathrm{MAb}$ had bound to these proteins. The blot also showed that there was a distribution of intact molecule and fragment $A$ in both toxoid and toxin samples. The intact molecule predominated in the tracks containing toxoid (1,3 and 5), whereas toxin was more readily dissociated (tracks 2, 4 and 6).

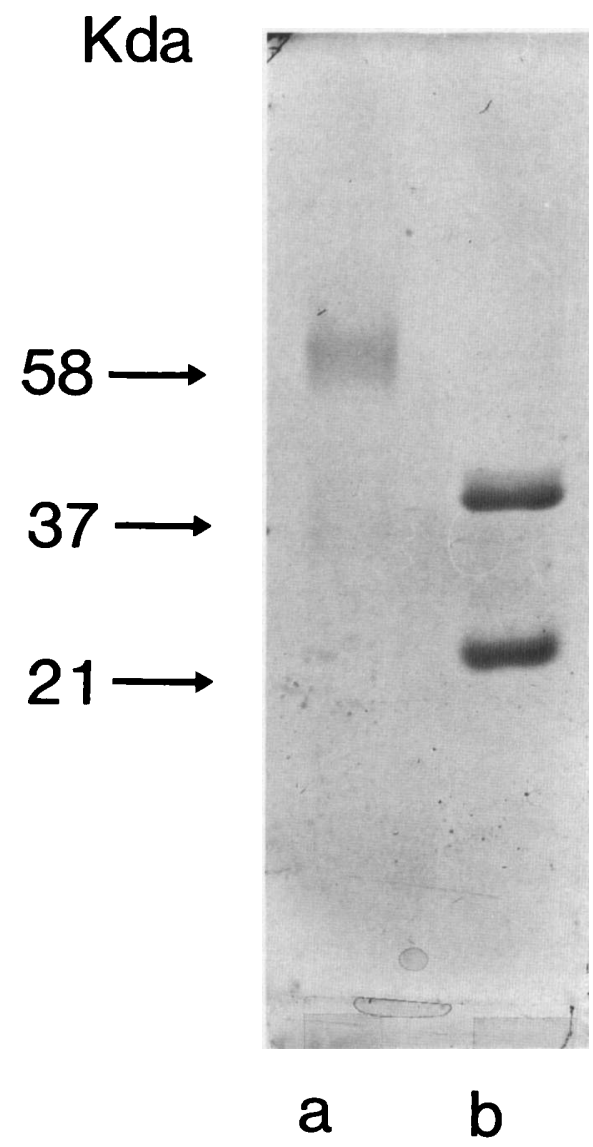

Fig. 1. Separation of diphtheria toxoid (a) and toxin (b) by SDSPAGE. Toxoid remained intact, with a single major band $(58 \mathrm{Kda})$; toxin dissociated into two fragments, $\mathrm{A}(21 \mathrm{Kda})$ and B (37 Kda).

\section{Activity of purified $M A b$}

Plates were coated with toxin or toxoid, $0.425 \mathrm{Lfu} /$ well. Doubling dilutions of each purified MAb, from 1 in 500, were added. Bound antibody was detected with anti-mouse polyvalent immunoglobulins conjugated to alkaline phosphatase. A consistently stronger signal was obtained with toxin than with toxoid, although both MAbs were raised against the toxoid.

\section{Detection of toxin in culture supernates by EIA}

FITC conjugates were prepared from purified MAbs 1 and 2. Preliminary experiments were done to determine the effect of using either the same $\mathrm{MAb}$ as both capture and detecting antibody, or one MAb to capture and the other to detect. Wells of a microtitration plate were coated with either MAb 1 or 2. Serial dilutions of toxin were added, and also either FITC-conjugated MAb 1 or 2 . When MAb 1 was used for both capture and detection, the EIA result was negative. Coating with MAb 1 and detecting with MAb 2 (MAb 1/2) resulted in lower OD readings than coating with MAb 2 and detecting with $\mathrm{MAb} 1$. The latter was roughly equivalent to coating and detecting with MAb 2.

With both the MAb 1/2 and MAb 2/1 sequences, toxin could be detected at a dilution of $5 \times 10^{-5}$ $\mathrm{Lfu} / \mathrm{ml}$. In initial experiments with culture supernates, tests were performed in duplicate, with MAb $1 / 2$ and MAb 2/1 sequences. Later, when all the culture supernates were tested in the same experiment (fig. 3), the sequence MAb 2/1 was used.

A total of 78 strains, including four toxigenic strains of $C$. ulcerans, was tested by EIA for toxin activity. The results were very clear, and the strains could be divided into two distinct groups by visual examination of the plate for the presence of colour in each well. Measurement of the OD at $450 \mathrm{~nm}$ confirmed that there was a significant difference between the EIA positive (tox ${ }^{+}$) and the EIA negative (tox ${ }^{-}$) supernates (fig. 3). For all except two of the toxin-positive strains, the OD was $>1.0$ when grown in both media. When grown in Elek broth, $32(78 \%)$ of 41 positive strains gave OD values $>1.5$, compared with only 21 of the same strains (51\%) grown in PPM medium. In contrast, all toxin-negative strains, except one grown in PPM medium, gave OD values $<0 \cdot 1$, usually $<0.05$.

Five strains from the NCTC were tested. Two of these gave consistently low values with both media. Three control strains for the Elek test gave the expected results in the EIA test, two positive and 


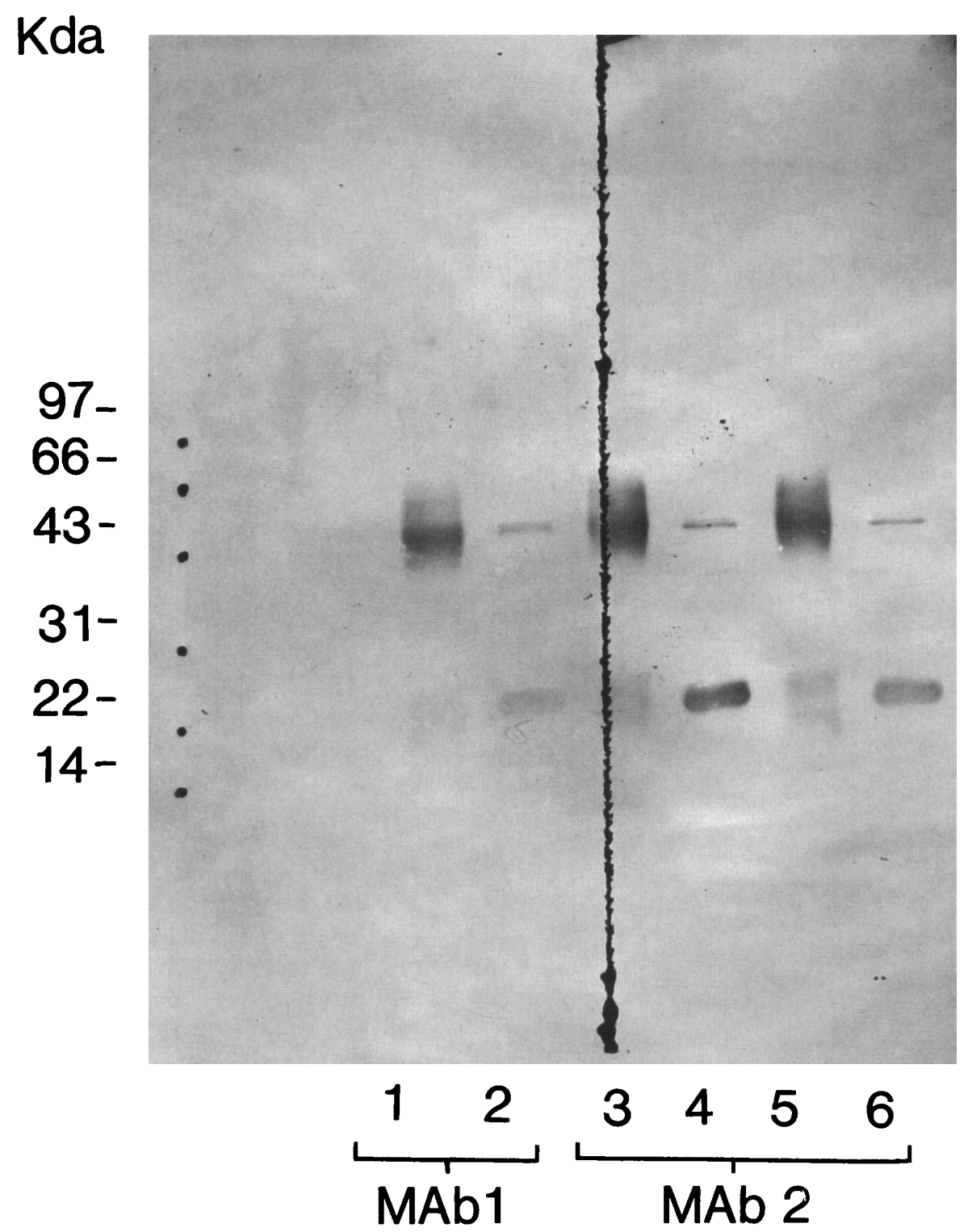

Fig. 2. Nitrocellulose blot of diphtheria toxoid and toxin, separated by SDS-PAGE: toxoid in tracks 1, 3 and 5 , toxin in tracks 2,4 and 6; tracks 1 and 2 stained with MAb 1, tracks 3-6 with MAb 2.

one negative, but there was no significant difference in OD between the strongly toxigenic (NCTC 10648) and the weakly toxigenic (NCTC 3984) strains. The OD values of these three strains were similar to those of recent isolates.

\section{Influence of growth medium on EIA values}

Of the 41 strains that were positive by EIA, the OD with Elek broth was higher than with PPM medium for 32 strains. PPM cultures gave higher readings in five cases, and there was no appreciable difference with four strains.

Comparison of EIA with other methods of toxin detection

All strains tested by EIA were tested also by the Elek method (see table); and 18 were inoculated into guinea-pigs for the virulence test, including all with which there was a discrepancy between the EIA and the Elek results. 

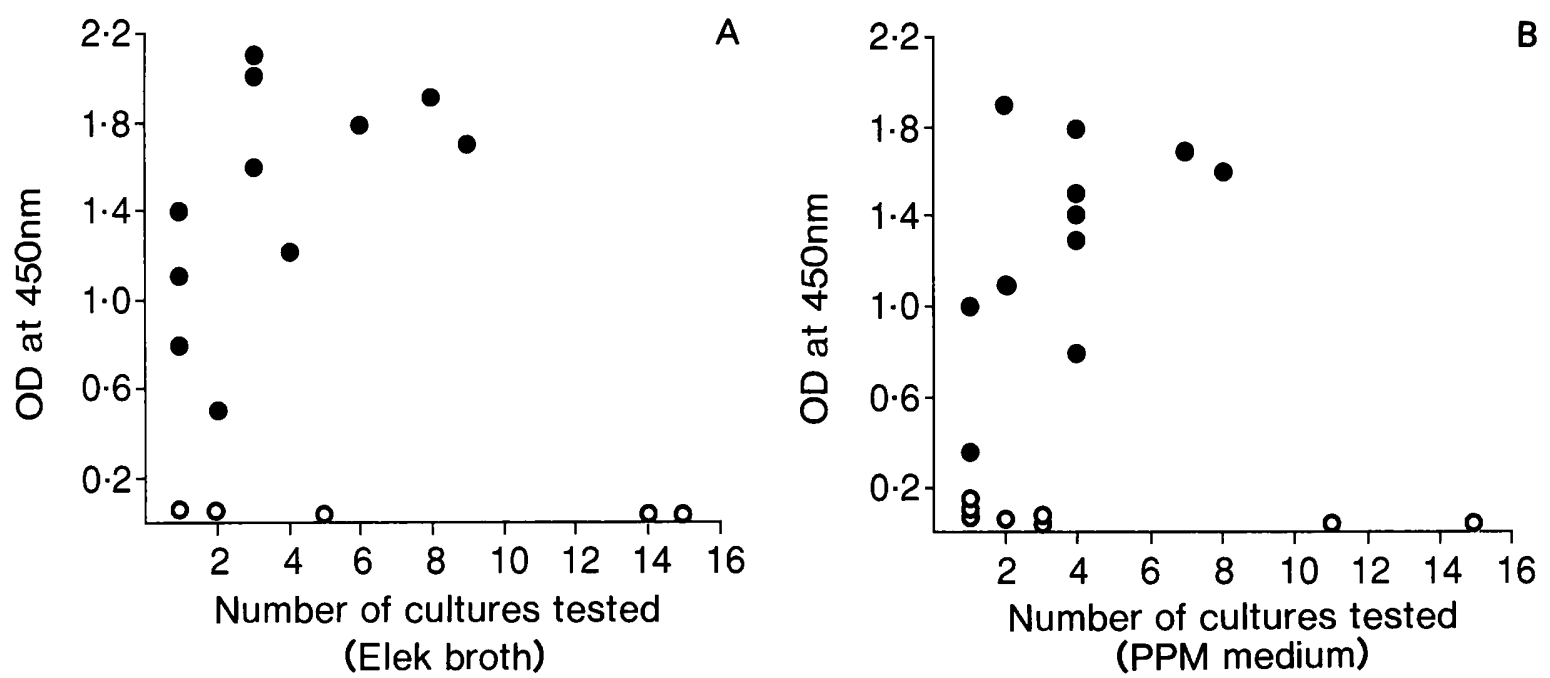

Fig. 3. Detection of diphtheria toxin by EIA. Whether cultures were grown in Elek broth (fig. 3A) or PPM medium (fig. 3B), there was a clear difference between EIA-positive $(O)$ and EIA-negative strains $(O)$, though in general the positive strains gave higher readings from Elek broth (see text).

There was agreement between the EIA and Elek results with 74 of the 78 strains tested. Of these, 14 were also injected into guinea pigs, and again there was agreement. There were discrepancies with four strains, all from the Canadian collection. All four strains were EIA positive. This was confirmed by repeated testing with the same culture supernates and also with a fresh culture of each strain. Two gave equivocal results in our Elek test which were difficult to interpret but were most probably weakly positive. However, only one was virulent in a

Table. Comparison of enzyme immunoassay (EIA), the Elek test and guinea-pig inoculation, for the detection of toxin production by strains of $C$. diphtheriae

\begin{tabular}{c|ccc}
\hline & \multicolumn{3}{|c}{ Detection of toxin by } \\
\cline { 2 - 4 } $\begin{array}{c}\text { Number } \\
\text { of strains }\end{array}$ & EIA & $\begin{array}{c}\text { Elek } \\
\text { test }\end{array}$ & $\begin{array}{c}\text { Virulence in } \\
\text { guinea-pigs }\end{array}$ \\
\hline 5 & - & - & - \\
32 & - & - & NT \\
$28^{*}$ & + & + & NT \\
$9^{*}$ & + & + & + \\
$1 \dagger$ & + & - & - \\
$1 \neq$ & + & - & - \\
$1 \dagger$ & + & $(+)$ & - \\
$1 \dagger$ & + & $(+)$ & + \\
\hline
\end{tabular}

NT, Not tested.

$(+)$, Weak positive.

* Includes two strains of $C$. ulcerans.

+ Designated as tox ${ }^{+}$by the referring laboratory.

$\ddagger$ Designated as to ${ }^{-}$by the referring laboratory. guinea-pig, causing death within $48 \mathrm{~h}$. Animals inoculated with each of the other three remained well for 14 days after injection.

\section{Discussion}

Diphtheria is now a rare disease in many parts of the world. During 1980-1986 only 27 cases were reported in England and Wales, ${ }^{14}$ mainly imported from abroad. However, outbreaks may still occur among susceptible individuals, as illustrated in a group of alcoholics in Sweden ${ }^{15}$ with 13 clinical cases and 65 carriers. Despite high levels of immunisation in children, serological surveys in Sweden have shown that $19 \%$ of people under 20 years and $68 \%$ over 60 years had antibody below the protective level of $0.01 \mathrm{IU} / \mathrm{ml}^{16}$ In similar studies in Britain, $35 \%$ of the population were susceptible. ${ }^{17}$ Therefore, the need for laboratory identification of toxigenic strains of $C$. diphtheriae still exists.

Possibly even more emphasis is now placed on bacteriological studies because diphtheria is often not considered in the initial diagnosis. ${ }^{18}$ The carriage of non-toxigenic strains is not uncommon. ${ }^{19}$ Therefore, it is important to identify toxinproducing strains accurately in the laboratory, primarily to confirm the diagnosis of diphtheria but also to contain the possible spread of the disease by tracing contacts who may be carriers.

Toxigenicity is usually assessed by the Elek test with hyperimmune horse antitoxin. Non-specific precipitation lines may occur and lead to confusion, particularly if the plate is incubated for $48 \mathrm{~h}$ or 
longer. ${ }^{1}$ Also the amount of toxin produced by a strain depends on the concentration of iron in the medium $^{20}$ and, therefore, if the test conditions are not optimal, erroneous results may be reported. Because the Elek test is performed infrequently in most laboratories, this is a serious problem. ${ }^{2}$ Confirmatory tests are therefore required. In the present study, MAbs have been used in an immunoassay to detect toxin in culture supernates.

A comparison of PPM medium and Elek broth was made because both media had been used previously in other studies of toxin production. Although the $\mathrm{OD}_{450}$ was higher for the majority of strains with Elek broth, the division into EIApositive and EIA-negative strains was the same irrespective of the growth medium.

Our results showed that there was agreement between the Elek test and EIA for $96 \%$ of strains tested. Identical results were obtained when $18 \%$ of these isolates were tested for virulence in guineapigs. With one strain, EIA confirmed a weak positive Elek result which was also substantiated by a positive guinea-pig test. The EIA appeared to give false positive results with three isolates on the basis of negative guinea-pig tests. Two of these strains were also negative in our Elek test although one had been designated as a toxin producer by the referring laboratory. Since both of our MAbs were directed against the $\mathrm{A}$ fragment of diphtheria toxin, it is unlikely that a strain that gave a positive reaction in the EIA would fail to produce toxin. However, it is possible that a strain producing a defective, inactive toxin might give a positive EIA but be avirulent in a guinea-pig. In such a case, a positive result might be expected also in the Elek test.

It is an advantage if a test for toxin production provides quick results. Antibody-coated plates were stable for several weeks after storage at $4^{\circ} \mathrm{C}$, and are, therefore, ready for immediate use. Cultures are grown for $18 \mathrm{~h}$, and the EIA test takes $5 \mathrm{~h}$ to perform. Therefore the EIA results are available within 2 days of receiving the culture.

The EIA could detect diphtheria toxin at a concentration of $c .5 \times 10^{-5} \mathrm{Lfu} / \mathrm{ml}$, or $88 \mathrm{pg} / \mathrm{ml}$. In other reports, the sensitivity has varied widely: $10^{-6} \mathrm{Lfu} / \mathrm{ml},{ }^{21} 10 \mathrm{ng}$ of toxin $/ \mathrm{ml}\left(5.7 \times 10^{-3}\right.$ $\mathrm{Lfu} / \mathrm{ml}),{ }^{22} 0.6 \mathrm{ng} / \mathrm{ml}\left(3.4 \times 10^{-4} \mathrm{Lfu} / \mathrm{ml}\right),{ }^{11}$ assuming that $1 \mathrm{Lfu}$ is equivalent to $1.75 \mu \mathrm{g}$ of toxin protein. ${ }^{23}$

Nielsen et al. ${ }^{22}$ described a double antibody sandwich ELISA in which horse antitoxin was used as the capture antibody and MAb for detection. Bacteria were grown directly in the ELISA plate, which presented a safety hazard; to minimise this, ethanol was added to the wells before the bacteria were washed out. This may explain the low OD values for their toxigenic strains. We have used filtered culture supernates, with no safety hazard; and the average OD for toxigenic strains grown in Elek broth was 1.65.

In immunoblotting experiments, both of our MAbs bound to intact toxin and to fragment A. By comparison, Hayakawa et al. ${ }^{24}$ studied 14 MAbs produced by immunisation with toxoid, and only two of these bound to fragment A. Our preliminary EIA experiments suggested that MAb 1 and MAb 2 recognised different epitopes, and that MAb 1 may be directed against an epitope which is present or accessible only in low concentration.

This study has shown that EIA provides an additional confirmatory test for diphtheria toxin which should be useful in a reference laboratory. Although it gives occasional false-positive results, it does not appear to give the equivocal results sometimes found with the Elek test.

\section{REFERENCES}

1. Davies JR. Elek's test for the toxigenicity of Corynebacteria. In: Davies JR, Glencross EJG, Marks J, Plow CD, Thomas MEM. Laboratory Methods 1. Public Health Laboratory Service Monograph Series no. 5. London, HMSO. 1974: 1-7.

2. Snell JJS, DeMello JV, Gardner PS, Kwantes W, Brooks R. Detection of toxin production by Corynebacterium diphtheriae: results of a trial organised as part of the United Kingdom National External Microbiological Quality Assessment Scheme. J Clin Pathol 1984; 37: 796-799.

3. Russell WC, Patel G, Precious B, Sharp I, Gardner PS. Monoclonal antibodies against Adenovirus Type 5: preparation and preliminary characterization. $J$ Gen Virol 1981 ; 56: 393-408.

4. Tedder RS, Yao JL, Anderson MJ. The production of monoclonal antibodies to rubella haemagglutinin and their use in antibody-capture assays for rubella-specific IgM. J Hyg (Lond) 1982; 88: 335-350.

5. Steinbuch $M$, Audran $R$. The isolation of $\mathrm{IgG}$ from mammalian sera with the aid of caprylic acid. Arch Biochem Biophys 1969; 134: 279-284.

6. Samuel D, Patt RJ, Abuknesha RA. A sensitive method of detecting proteins on dot and Western blots using a monoclonal antibody to FITC. $J$ Immunol Methods 1988; 107 : 217-224.

7. Laemmli UK. Cleavage of structural proteins during the assembly of the head of bacteriophage T4. Nature 1970 ; 227: 680-685.

8. Towbin H, Staehelin T, Gordon J. Electrophoretic transfer of proteins from polyacrylamide gels to nitrocellulose 
sheets: procedure and some applications. Proc Natl Acad Sci USA 1979; 76 : 4350-4354.

9. Leary JJ, Brigati DJ, Ward DC. Rapid and sensitive colorimetric method for visualizing biotin-labeled DNA probes hybridized to DNA or RNA immobilized on nitrocellulose: Bio-blots. Proc Natl Acad Sci USA 1983; 80: 4045-4049.

10. Hallas G. The use of SDS-polyacrylamide gel electrophoresis in epidemiological studies of Corynebacterium diphtheriae. Epidemiol Infect 1988; 100 : 83-90.

11. Krech T, Wittelsburger C. Immunologische Methoden zum Nachweis von Diphtherie-Toxin (Passive Haemagglutionation und ELISA zum Toxinnachweis aus Kulturen und im Serum) Zentralbl Bakteriol Mikrobiol Hyg $(A)$ 1987; 265 : 124-135.

12. Sottnek FO, Miller JM. Isolation and identification of Corynebacterium diphtheriae. US Department of Health and Human Services. Atlanta, Public Health Service, Center for Disease Control. 1980: 1-14.

13. Murphy, JR. The diphtheria toxin structural gene. Curr Top Microbiol Immunol 1985; 118: 235-251.

14. Communicable disease statistics. Office of Population Censuses and Surveys, OPCS series, MB2 no. 13. London, HMSO. 1986; 6.

15. Bjorkholm B, Olling S, Larsson P, Hagberg L. An outbreak of diphtheria among Swedish alcoholics. Infection 1987; 15: 354-358.

16. Karzon DT, Edwards KM. Diphtheria outbreaks in immunized populations (Editorial). $N$ Engl J Med 1988; 318: 41-43.

17. Sheffield FW (Ad-hoc Working Group). Susceptibility to diphtheria. Lancet 1978; 1:428-430.

18. Warwick-Brown NP, Lund VJ. Diphtheria-a forgotten disease. Br J Clin Prac 1987; 41 : 580-582.

19. Simmons LE, Abbott JD, Macaulay ME, et al. Diphtheria carriers in Manchester: simultaneous infection with toxigenic and non-toxigenic mitis strains. Lancet 1980; 1: 304-305.

20. Pappenheimer AM, Johnson SJ. Studies in diphtheria toxin production. I: the effect of iron and copper. Br J Exp Pathol 1936; 17: 335-341.

21. Ionescu M, Dumitrescu A, Stefanescu M, Szegli G. ELISA for toxinogenesis identification in Corynebacterium diphtheriae, diagnostic value. Arch Roum Pathol Exp Microbiol 1986; 45: 5-12.

22. Nielsen PB, Koch C, Friis H, Heron I, Prag J, Schmidt J. Double-antibody sandwich enzyme-linked immunosorbent assay for rapid detection of toxin-producing Corynebacterium diphtheriae. J Clin Microbiol 1987; 25 : 1280-1284.

23. Barksdale L. Corynebacterium diphtheriae and its relatives. Bacteriol Rev 1970; 34: 378-422.

24. Hayakawa S, Uchida T, Mekada E, Moynihan MR, Okada Y. Monoclonal antibody against diphtheria toxineffect on toxin binding and entry into cells. $J$ Biol Chem $1983 ; 258$ : $4311-4317$. 
